\title{
SIG E ARQUEOLOGIA: ENSAIO PARA A COMPREENSÃO DO ALTO DOURO DO III E II MILÉNIO A.C.
}

\author{
SOFIA LACERDA ${ }^{(1)}$
}

Resumo:

\begin{abstract}
Com este ensaio pretendeu-se complementar o estudo do Alto Douro do III e II milénio a.C. oferecendo uma perspectiva cartesiana do espaço como complemento aos estudos que têm sido feitos com base na percepção presencial de investigadores como João Muralha Cardoso, Vítor Oliveira Jorge, Susana Oliveira Jorge, Ana Margarida Vale, António Sá Coixão e outros.

Esta análise permitiu testar a falibilidade dos Sistemas de Informação Geográfica (SIG), ferramenta que possibilitou a concretização de uma série de mapas (Heatmap, Terrain Profile, Viewshed, etc.) que permitiram percepcionar o território à macro escala e reflectir sobre a disposição e a relação entre sítios como Castanheiro do Vento e Castelo Velho, além de outros da mesma cronologia e território, mas que, sobretudo por falta de intervenções arqueológicas, não conhecemos tão bem. Entendeu-se que todos estes sítios, formando dois grandes núcleos, poderão ter funcionado de forma articulada; e que sítios como Castanheiro do Vento, Castelo Velho, Santa Columba ou Montes se situam em zonas que possibilitam um amplo controlo visual sobre o território, o que reforça noções como a de hierarquia e controle.
\end{abstract}

Palavras-chave: Pré-História Recente, Alto Douro, Paisagem, SIG.

\begin{abstract}
:
GIS and Archaeology: essay for the comprehension of Alto Douro in III and II millenium b.C

We intend, with this essay, to complement the study of the Alto Douro region, between the 3rd and 2nd millenium b.C., offering a cartesian insight of this space, investigated by archaeologists such as João Muralha Cardoso, Vítor Oliveira Jorge, Susana Oliveira Jorge, Ana Margarida Vale and António Sá Coixão.

This analysis allowed us to test the fallibility of Geographic Information Systems (GIS) - a tool that allowed us to perform spacial analysis operations (Heatmaps, Terrain Profiles, Viewshed Analysis, etc.). Thus, we could understand the territory at a larger scale, and reflect on how sites such as Castanheiro do Vento and Castelo Velho are disposed and related, as well as other ones from the same period, that due to the lack of archaeological research, we don't know quite well. It is understood that all these sites, which form two groups, that might have worked in an articulated way; and that sites as Castanheiro do Vento, Castelo Velho, Santa Columba or Montes, located in areas which allowed a good visual control over the territory, reinforce concepts as hierarchy and control.
\end{abstract}

Keywords: Late Prehistory, Alto Douro, Landscape, GIS

Received: 4 May, 2016; Accepted: 10 November, 2016

\section{ESPAÇOS, PAISAGENS E LUGARES}

"O mundo não é um acontecimento nem um comportamento, mas o espaço, o lugar, o cenário onde os eventos ocorrem e os comportamentos têm lugar." (ALARCÃO, 2000: 38).

Embora o propósito deste artigo não seja desenvolver as problemáticas que demarcam o estudo da paisagem e as disciplinas que a ela se dedicam, importa fazer um breve périplo em torno de algumas ideias que ajudam a contextualizar este ensaio.

Muitos arqueólogos procuram entender a identidade do território, conceito que inclui uma paisagem onde lugares e mobilidades se conectam (CARDOSO 2007: 417), através de vestígios materiais, tangíveis, enquadrando-os numa determinada corrente teórica e recorrendo a diferentes disciplinas. Análises espaciais do território e seus recursos, i.e. a ponderação de dados geográficos tendo em conta as suas características espaciais (UNWIN 1981: 212), recorrem sobretudo à Geografia, salientando- se para o efeito os SIG (Sistemas de Informação Geográfica), aplicação que surge na década de 60 do século passado; o processamento computacional da informação espacial até hoje não parou de crescer e tornou-se cada vez mais eficiente, permitindo vários tipos de abordagens ao espaço. A sua utilidade é manifesta e reside, sobretudo, na sua capacidade de organizar dados georreferenciados, criar relações entre eles e permitir, através de processos automáticos, a apreensão de uma percepção diferente de uma determinada realidade, o que pode levar o investigador a conclusões que de outra forma não seriam possíveis. Como ferramenta da Geografia, os SIG foram pensados para gerir recursos naturais e humanos e, nessa medida, são úteis essencialmente para uma abordagem política e económica do território. "Geographic Information Systems (GIS), in particular, have opened new avenues for comprehending and interpreting land and resource use at unanticipated scales" (ZEDEÑO 2008: 211). Com base neste princípio, procurou-se testar esta ferramenta no Alto Douro do III e II milénio a.C., ofere-

${ }^{(1)}$ Mestranda em Arqueologia e Território na Faculdade de Letras da Universidade de Coimbra. Contacto: a.sofialacerda@hotmail.com 
cendo um complemento cartesiano aos estudos que autores como João Muralha Cardoso têm aqui desenvolvido: "A utilização de tecnologia SIG (Sistema de Informação Geográfica) teria sido desejável, mas apenas numa perspectiva complementar. Privilegiou-se a observação no local e a percepção de estar na "paisagem" (2007: 314).

Para compreender a construção de um território, muitos arqueólogos, inspirados em antropólogos como Julian Steward ou Leslie White, têm recorrido a perspectivas neoevolucionistas, i.e., empiristas, baseadas em dados quantificáveis para avaliar a evolução cultural, assim como à combinação de modelos antropológicos com elementos da geografia, ecologia e biologia, ou ainda a teorias sociais pós-modernas. Frente às orientações funcionalistas que recorrem à observação empírica directa e que se explicam de forma objectiva, surge uma concepção distinta, que encara a paisagem como um produto sociocultural: começa-se a entender que o espaço é mais que um simples elemento natural, que é também uma organização social e cultural, e que em si contem o universo cognitivo de quem o viveu. (CRIADO BOAdO 1999: 4-5; BETTENCOURT \& Alves 2009; Fagude \& PiUZANa 2010: 207). De acordo com González Villaescusa (2006: 29) "El paisaje tiene, pues, frente a naturaleza o medio, una conotación antrópica, es decir, se trata de medir el impacto de la espécie humana en la historia del medio ambiente".

A paisagem como objecto observado "que vincula al hombre com el entorno natural a través del tiempo" (SÁNCHEZ Yustos 2010: 141), tem sido pensada desde diferentes pontos de vista (cf. ANSCHUETZ et al. 2001; CRIADO BOADO 1999; GONZÁlEZ VILLAESCUSA 2006; OREJAS 1995; 1998; OREJAS et al. 2002; SÁNCHEZ YUSTO 2010). Interessa particularmente distinguir duas dimensões, aquelas que melhor retratam as correntes teóricas processualista e pós-processualista: a económica ou materialista e a simbólica, cada uma traduz a forma como os homens do passado "definen, moldean y utulizan el espacio en cada tiempo concreto" (SÁNCHEZ YUSTO 2010: 141). A dimensão económica da paisagem implica a adopção de uma óptica ecológica e funcionalista, associada a várias relações e factores capazes de fornecer uma visão e contextos holísticos. Surgiu no âmbito da New Archaeology e proporcionou um significativo ímpeto teórico-metodológico nos estudos espaciais, com propostas como a teoria do lugar central, a teoria do alcance médio, os polígonos Thiessen e outros (cf. GARCÍA SANJUÁN 2005: 198-234).

Com o decorrer dos anos começa-se a reconhecer que a vertente antropomórfica do espaço vai mais além das alterações físicas, que implica também padrões comportamentais relacionados com as dimensões sociais e ideológicas. Desta forma, na última década do século passado a arqueologia britânica começou a desenvolver estudos da paisagem na sua dimensão simbólica, i.e. ao imaterial, ao imaginado e pensado. No entanto, importa reconhecer que estamos perante um universo alegórico, pois é inequívoco o carácter subjectivo destas evidências. A dimensão simbólica da paisagem tem necessariamente um carácter fenomenológico e hermenêutico e encaminha-nos até à consciência perceptiva e experiência sensorial (TILLEY 1994). Esta dimensão é pós-processual por excelência e contrapõe-se à arqueologia funcional, que é o processualismo.

Importa, porém, entender que esta é uma visão muito resumida das formas que a paisagem pode assumir e talvez aquela que melhor expressa duas formas diferentes de fazer arqueologia (CARDOSO 2007: 307-313). Criado Boado (1999: 6) fala numa Arqueologia Total ao definir para a paisagem as seguintes dimensões: a) física, onde colaboram disciplinas como a Paleoecologia ou a Geoarqueologia; b) social, é o meio construído pelo homem, sobre o qual se desenvolvem relações entre indivíduos ou grupos; c) simbólica, na qualidade de espaço pensado.

É nesta fase que podemos entender uma das grandes críticas ao SIG aplicado à arqueologia: é que ele projecta um espaço cartesiano, i.e., mensurável, geométrico, matemático, desvinculado da realidade cognitiva e, portanto, limitado a análises funcionais (CARDOSO 2007: 314; PELLINI 2008: 172 -173). Porém, isto só constitui um problema efectivo se fizermos uso exclusivo destes softwares (ArcGIS, Quantum GIS, etc.), ou seja as análises feitas através dos SIG devem constituir um complemento e não um fim em si. Aplicar de forma exclusiva os SIG pode efectivamente retirar valor ao trabalho, mas um trabalho que use SIG como ferramenta complementar é necessariamente um trabalho com mais valor. A importância dos SIG para a arqueologia é manifesta, desde que bem utilizados, como ferramenta que constitui uma base de dados de acesso rápido e fácil, que por sua vez permite simular uma série de efeitos espaciais.

Em suma, a paisagem, como objecto de estudo da Arqueologia, inclui um espaço e uma percepção. $\mathrm{O}$ primeiro caracteriza-se por ser uma realidade física, "[...] não é habitar o mundo, mas sim representá-lo." (CARDOSO 2007: 304), enquanto o segundo se define como sendo sensorial, ideal e simbólico, como escreve Cardoso (idem: 312 ) "Aqui a percepção é uma actividade de todos os sentidos [...]".

Frente a isto, crê-se que o mais sensato é uma atitude livre de facciosismos, adoptando uma postura baseada na premissa de que a interacção de filosofias e métodos nos conduz a um conhecimento cada vez mais fidedigno do nosso objecto de estudo. Esta postura implica, na minha concepção, reconhecer a complementaridade de correntes arqueológicas, ideia já largamente tratada por Alarcão (1996). Quero com isto dizer que a Arqueologia Processualista não vem invalidar a Arqueologia Pós- 
Processualista, e vice-versa: elas complementam-se e isoladas são incompletas (para saber mais cf. Alarcão 1996; 2000; Alarcão \& Jorge 1997).

\section{O ALTO DOURO NO III E II MILÉNIO A.C.}

O espaço, actual ou remoto, inclui uma dimensão física (geologia, geomorfologia, tipos de solos, recursos hídricos etc.), biótica (ecossistemas) e antrópica, sendo a dimensão antrópica do espaço a dos lugares ou sítios arqueológicos (CARDOSO 2007: 301-306); ou seja, por espaço entendamos aquilo que existe a priori, por lugar aqueles sítios que, no espaço, foram vividos.

A área de estudo que tratamos aqui situa-se no Alto Douro, entre o rio Douro a norte, serra da Marofa a sul, rio Torto a oeste e a ribeira de Aguiar a este; incluindo os seguintes concelhos: Carrazeda de Ansiães, Figueira de Castelo Rodrigo, Mêda, Penedono, Pinhel, São João da Pesqueira, Torre de Moncorvo e Vila Nova de Foz Côa. Esta área encontra-se dominada pela bacia hidrográfica do rio Douro, que inclui, entre outros, afluentes como o rio Távora, rio Torto, ribeira de Teja, rio Vale da Vila, rio Côa, ribeira de Aguiar. Importa, por outro lado, salvaguardar para o facto dos mapas do presento texto estarem feitos de acordo com os contornos dos actuais concelhos por motivos sobretudo pragmáticos à hora da sua execução, o que significa que estas fronteiras não devem ser entendidas como demarcações do passado.

Em estudo estão 61 sítios do III e II milénio a.C. que se distribuem numa área total de $2887,91 \mathrm{~km}^{2}$ (Fig.1); no que respeita à distribuição dos sítios aqui georreferenciados, podemos observar com base no cálculo de densidade (Heatmap) ${ }^{1}$ executado sobre o MDT (Modelo Digital de Terreno), i.e. a representação da superfície terrestre, dois núcleos genéricos: um junto à margem sul do rio Douro e entre o rio Torto a oeste e o rio Côa a este; o outro, também ele situado a sul do Douro, mas mais a sul relativamente ao núcleo anterior e ocupando as duas margens em torno da parte medial do rio Côa, sendo essa ocupação mais significativa na margem esquerda (Fig.2).

A situação geológica destes núcleos parece ser a mesma, caracterizada por rochas eruptivas e metamórficas; a maior parte dos sítios localizam-se na zona do complexo xisto-grauváquico, os restantes numa zona de granitos e rochas afins e uma minoria numa zona de cascalheiras de planalto, arcoses da Beira Baixa, arenito e calcários (Fig.3).

Os sítios arqueológicos aqui registados têm em comum, desde logo, uma cronologia que nos remete para a Pré-História Recente. Todos estes sítios foram alvo de prospecção arqueológica (CARDOSO 2007; COIXÃo 1996), mas nem todos puderam ser escavados, e dentro dos que foram, saliente-se Castelo Velho, sítio escavado na íntegra, e por outro lado Castanheiro do Vento, ainda em processo de escavação / estudo. Tratam-se de sítios basilares neste ponto do conhecimento para entender a Pré-História Recente do Norte de Portugal e, por isso, justifica-se falar deles em particular.

Castelo Velho localiza-se na freguesia de Freixo de Numão, concelho de Vila Nova de Foz Côa. Situa-se a $681 \mathrm{~m}$ de altitude, num remate em esporão onde predominam os xistos. As análises de C14 indicaram uma ocupação que se situa entre 3000 a.C. a 1300 / 1200 a.C. (JORGE \& RUBINOS 2002). Segundo Susana O. Jorge $(2004 ; 2005)$, a história de Castelo Velho parece contar com quatro momentos distintos: 1) uma primeira ocupação, por volta de 3000 a.C., que incluiu estruturas de combustão, fossas, buracos de poste, um torreão, etc.; 2) um segundo momento, a partir de 2800 a.C., onde se construiu um sítio de planta elíptica, que incluiu um recinto, no interior do qual se construíram várias estruturas e uma torre central, e ainda uma rampa / talude e murete / talude; 3) A partir de 2300 a.C. documentam-se alterações no recinto e fora dele, fecharam-se acessos e surgiram novas estruturas; 4) finalmente, em $1300 / 1200$ a.C., encerra-se o monumento, petrificando-o. No início do presente século Susana Oliveira Jorge (2003a; 2003b; JORGE et al. 2007: 79) reformula o faseamento acima proposto, abandonando-o em detrimento de três momentos: 1) o anterior à construção do monumento que deveria situar-se na primeira metade do III milénio a.C.; 2) o momento de construção e vivências, até à segunda metade do II milénio a.C.; 3) finalmente, nas datas acima indicadas (alínea 4), o cerre do monumento. Esta mudança tem por base uma forma diferente de pensar: "procura-se uma teoria da acção no espaço ou um espaço permanentemente reconfigurado pela acção." (JORGE et al. 2007: 79).

O sítio monumental de Castanheiro do Vento, freguesia de Horta do Douro, concelho de Vila Nova de Foz Côa, data do Calcolítico e Bronze Antigo e Médio, ou seja, situa-se entre o III milénio a.C. e segunda metade do II milénio a.C. Num cabeço com c.730 metros de altitude erguem-se estruturas arquitectónicas complexas que tem vindo a ser escavadas e estudadas por vários autores (cf. CARDOSO 2007; CARDOSO et al, 2012; JORGE et al, 2002; 2003a; 2003b; VALE 2008-2009; VALE et al. 2006). As estruturas aí documentadas foram construídas com recurso a argila e pedra. A argila foi empregue quer para nivelar a superfície do substrato rochoso, quer como ligante, revestimento de estruturas pétreas e ainda para erguer paredes assentes sobre uma base pétrea; o substrato rochoso, por sua vez, foi utilizado como delimitador do sítio e maté-

${ }^{1} \mathrm{O}$ mapa de densidades produzido parte de um conjunto de pontos vectoriais (os sítios arqueológicos) e tem por base a estimativa de Kernel (para saber mais ver LUCAMBIO 2008). 


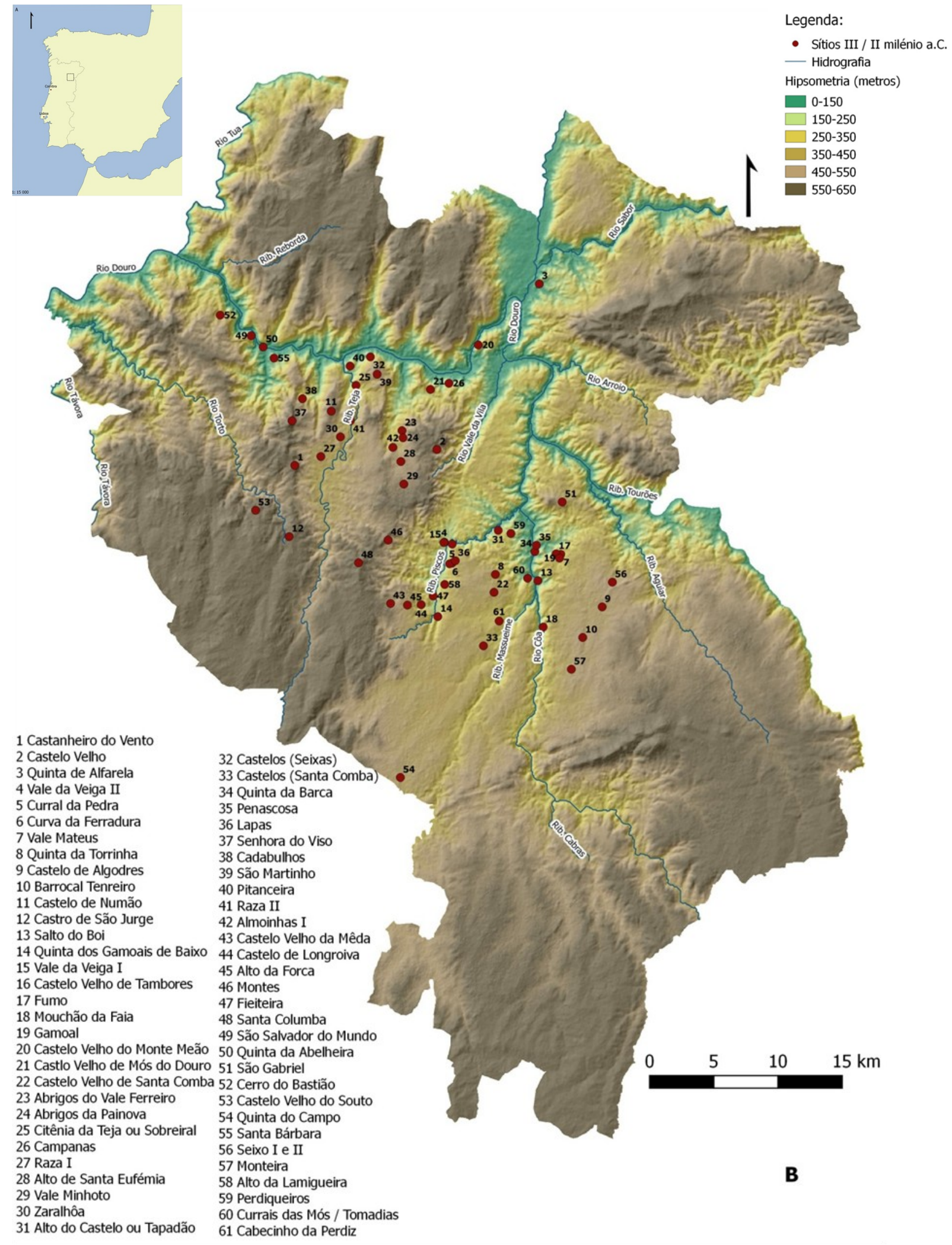

Fig. 1. MDT do Alto Douro, respectivos povoados do III e II milénio a.C. (B) e contextualização geográfica (A). Executado com QGIS 2.10.1 Pisa.

Fig.1. DTM of Alto Douro, respective settlements in III and II millennium b.C. (B) and its geographical contextualization (A). Made by QGIS 2.10.1 Pisa. 


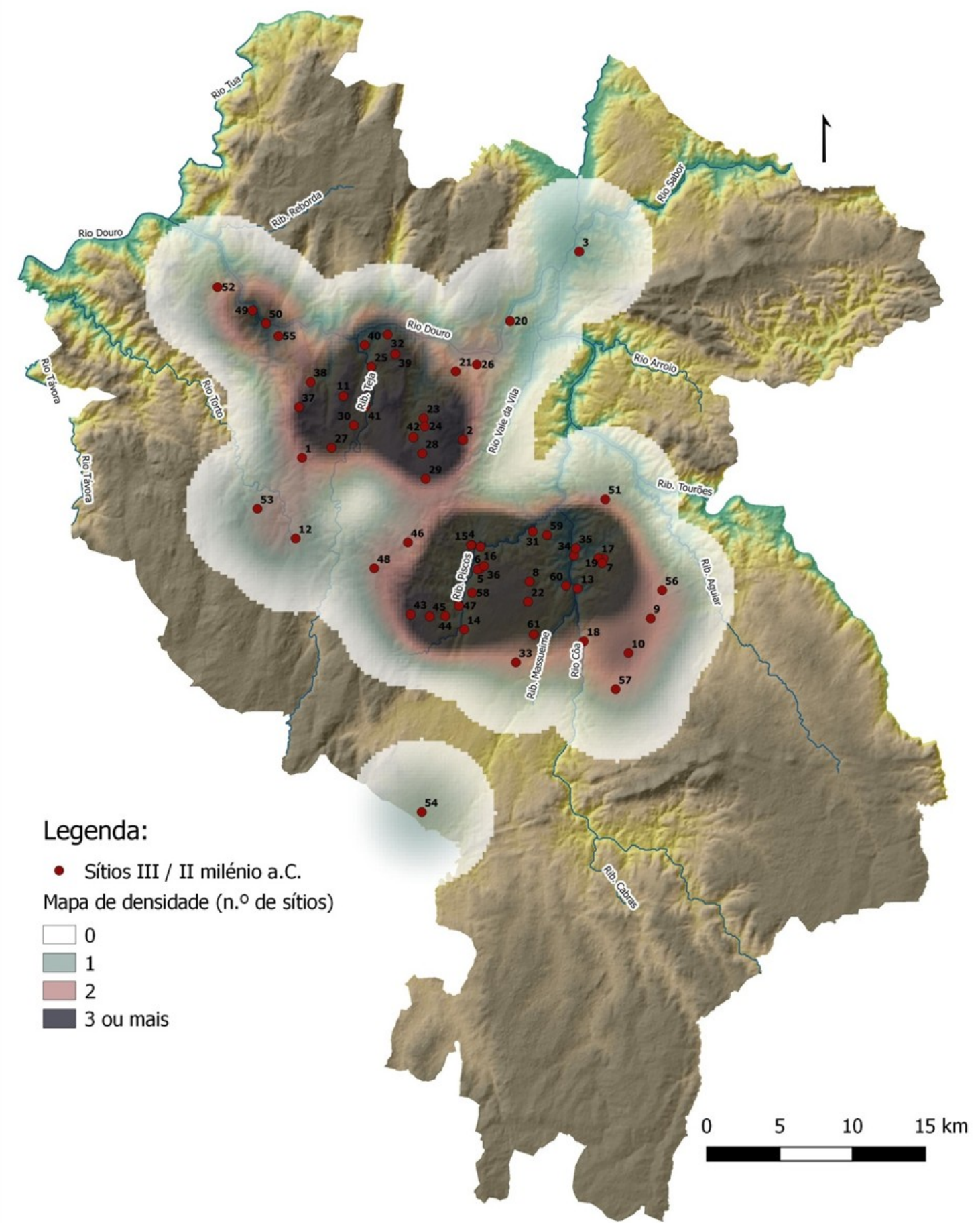

Fig. 2. Heatmap dos sítios do III e II milénio a.C. Executado com QGIS 2.10.1 Pisa.

Fig.2. Heatmap of settlements in III and II millennium b.C. Made by QGIS 2.10.1 Pisa.

ria-prima. Em termos de planta documentam-se segmentos de muretes, estruturas subcirculares (ou "bastiões"), estruturas circulares e passagens. De referir ainda a presença de um sistema de contrafortagem formado por taludes e lajes de xisto encostadas à base externa da estrutura, de forma a dar-lhe estabilidade, estas últimas eram por sua vez sustentadas por outras lajes que estavam fincadas ou atravessadas.

Estes dois sítios inserem-se no contexto de uma problemática maior - a dos recintos murados fechados. E ao chamar-lhes recintos murados estamos já a introduzir uma das questões mais interessantes que envolve esta problemática, que é precisamente a negação da interpretação tradicional destes sítios como povoados fortificados, i.e., a ideia de que estão em causa espaços habitacionais defensivos o que implica, em última instância, a existência de um estado de guerra durante o Calcolítico. A desconstrução desta interpretação remonta aos 


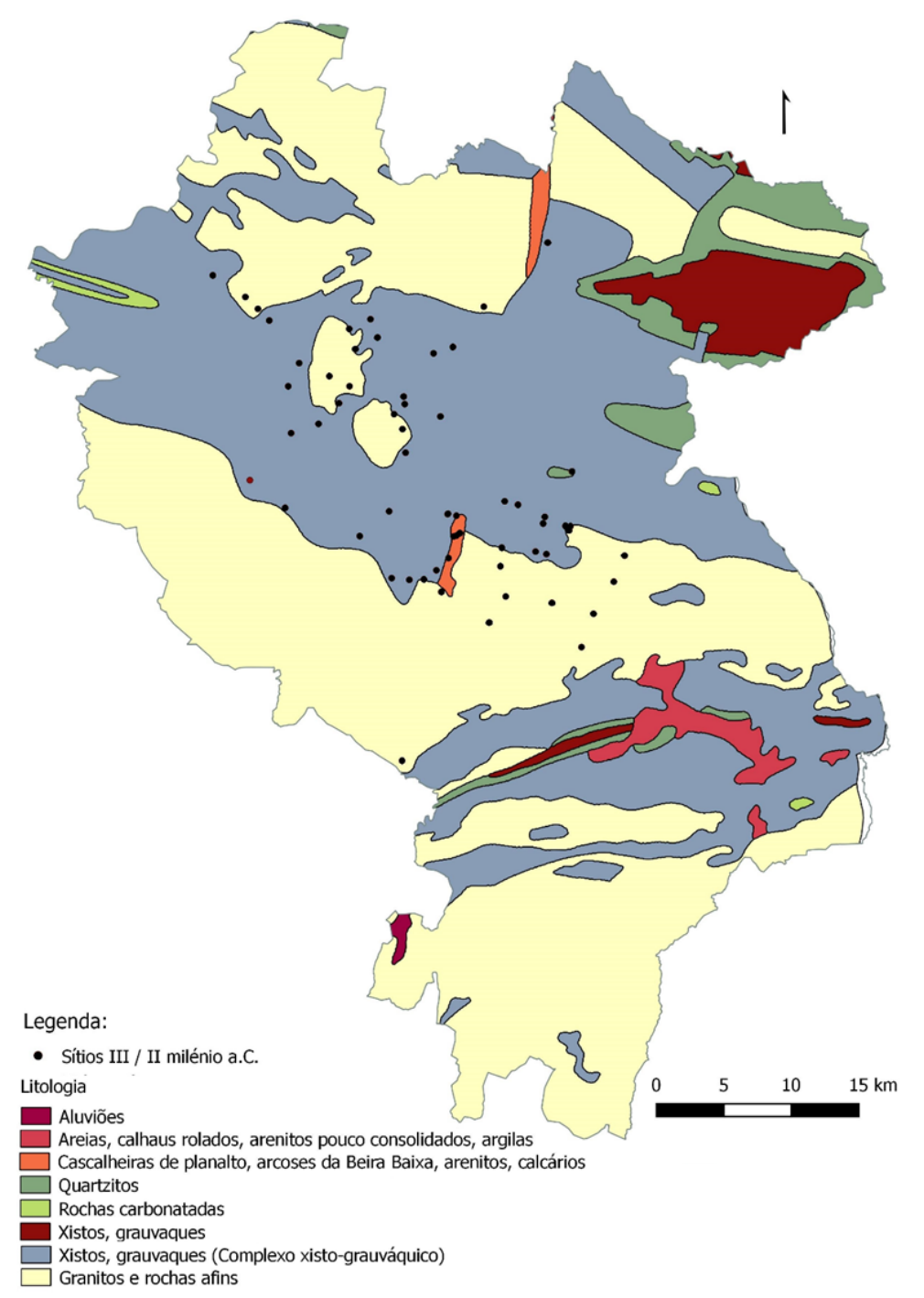

Fig. 3. Mapa Litológico do Alto Douro. Executado com QGIS 2.10.1 Pisa.

Fig.3. Lithological map of Alto Douro. Made by QGIS 2.10.1 Pisa.

anos 90 e é da autoria de Susana Oliveira Jorge (1994; JORGE et al. 2007) que, concomitantemente, salienta as noções de monumentalização, simbolismo e identidade - a ideia em causa configura-se "uma ruptura não só com a interpretação deste sítio particular, mas com a visão tradicional de lugares aparentemente similares na Península Ibérica" (JORGE et al. 2007: 77). "Os chamados "povoados fortificados" do Calcolítico português devem, assim, basicamente ser vistos como operadores de identidade e coesão social, e como lugares simbólicos de redistribuição, intercâmbio e troca com elites de outros grupos. Neste sentido, são monumentos." (JORGE \& JORGE 2000: 109).

A argumentação que S. O. Jorge (2003: 1920) utiliza para nulificar esta leitura funcionalista, sobretudo no caso de Castelo Velho, configura-se da seguinte forma: ausência de condições defensivas mínimas; os muros que cercavam este espaço não possuíam largura e altura significativa; as paredes que se erguiam sobre as bases pétreas eram, normalmente, construídas em materiais perecíveis; o número significativo de acessos/portas ao interior dos recintos; o facto de estes sítios estarem implantados em zonas de grande visibilidade e fácil ataque; ainda a necessidade de fundamentar um eventual estado de guerra. Desta forma, Castelo Velho "passa a ser visto como um dispositivo ao serviço da identidade comunitária em grupos debilmente hierarquizados" (JORGE et al. 2007: 77-78).

\section{CASTElO VELHO E CASTANHEIRO DO VENTO EM RELAÇÃO}

Aqui chegados entende-se uma similitude evidente entre Castelo Velho e Castanheiro do Vento, desde logo porque se inserem no mesmo intervalo cronológico relativo e numa mesma 
região, depois por se tratarem de recintos monumentalizados, com arquitecturas concordantes ora nas bases pétreas e nas paredes que se presume terem existido em materiais perecíveis. Ao traçar uma linha recta entre os dois sítios a fim de obter o perfil topográfico (Terrain Profile) que os inclui e separa, confirma-se que a implantação destes obedece, em termos genéricos, ao mesmo padrão: privilegia-se a altura, embora Castanheiro do Vento se localize a uma cota ligeiramente superior (730m) de Castelo Velho $(681 \mathrm{~m})$ e a potência paisagística (Fig. 4 e 5). Tudo isto permite ponderar uma eventual conexão entre sítios, que aliás não se deveria restringir a estes dois.

Um dos aspectos mais marcantes destes sítios monumentalizados é, além da visibilidade que os define, o alcance visual que eles possuem. Para o provar procedeu-se à execução de bacias de visão (viewsheds), i.e., ferramenta que permite calcular a área visível a partir de um determinado sítio, neste caso num raio de $20 \mathrm{~km}$ e à altura, a partir da superfície, de 1,70 m. As bacias de visão definem uma "landscape room" (FRY et al. 2004: 102), ou seja, uma unidade de percepção composta por um chão (superfície), paredes (fronteiras) e um tecto (céu).

Ao observarmos os resultados obtidos a partir

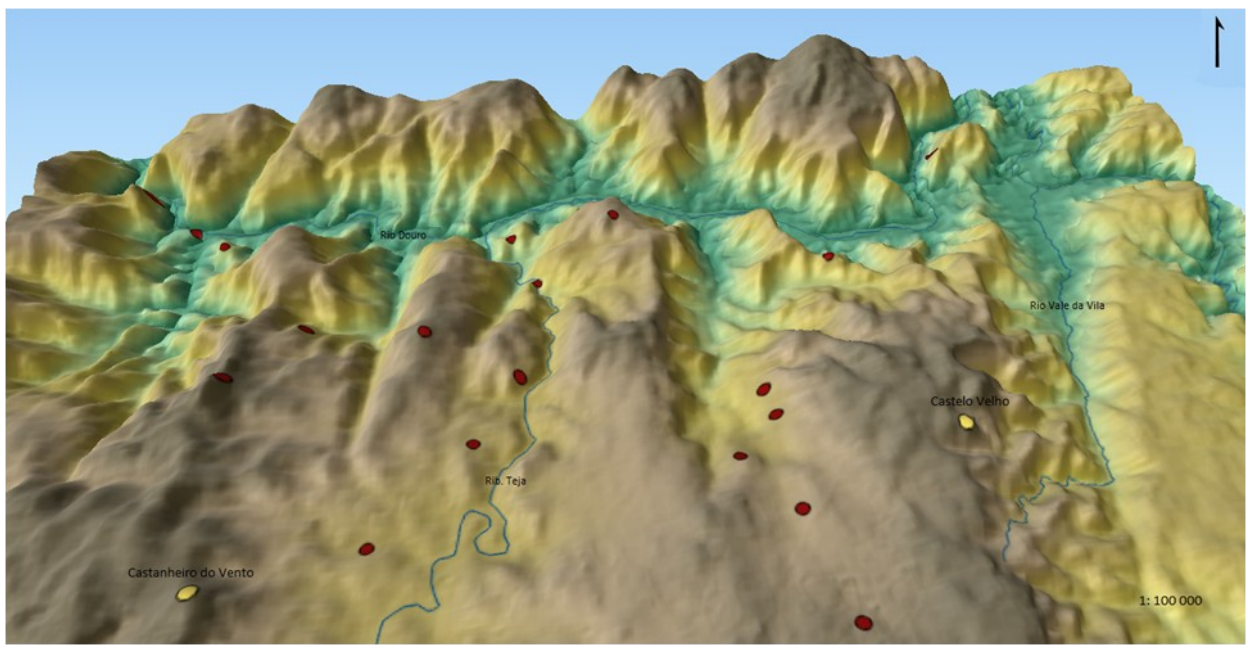

Fig. 4. Modelo 3D sobre MDT. Executado com o módulo Qgis2threejs do QGIS 2.10.1 Pisa. Fig.4. 3D Model over DTM. Made by Qgis2threejs, QGIS 2.10.1 Pisa.

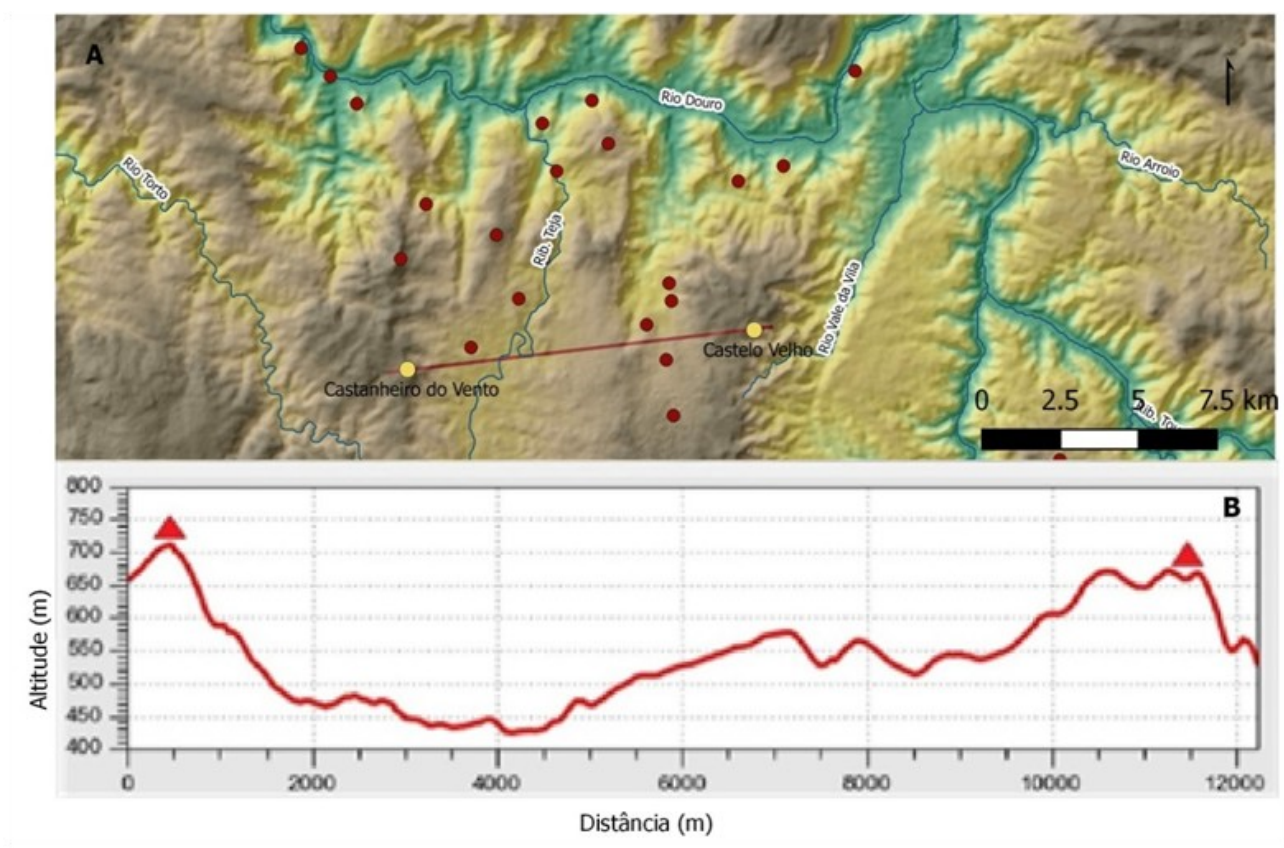

Fig. 5. Terrain Profile entre Castanheiro do Vento e Castelo Velho. Executado com o módulo Profile tool do QGIS 2.10.1 Pisa.

Fig.5. Terrain Profile between Castanheiro do Vento and Castelo Velho. Made by Profile tool, QGIS 2.10.1 Pisa. 
deste cálculo podemos perceber que há uma vasta extensão visível a partir de cada um destes sítios. De acordo com a figura 6, Castelo Velho tem uma potência visual diminuta para norte e sul relativamente à observável para sudoeste e sobretudo para nordeste, este e sudeste; no caso de Castanheiro do Vento predomina a visibilidade para norte e oeste, em detrimento do sul e este. Constatamos ainda que a amplitude visual de Castelo Velho é menor que a de Castanheiro do Vento, mas no que respeita a alcance, Castelo Velho parece ter mais que Castanheiro do Vento; ou seja a partir de Castanheiro do Vento observamos uma maior extensão do entorno próximo, enquanto em Castelo Velho temos maior alcance de uma extensão mais reduzida, mas como refere Jorge (2004: 595; 2005: 142145) a distância tal que se obtém a partir de alguns ângulos de Castelo Velho faz-nos falar em "paisagens abstractas"; interessa fazer uma nota para o facto da serra da Marofa, embora localizada a mais de $20 \mathrm{~km}$, ser visível a partir de ambos os sítios e, por este motivo, se inserir neste grupo das "paisagens abstractas" e constituir, segundo Cardoso (2007), uma crista quartzítica importante quer do ponto de vista geomorfológico, quer no que respeita a interpretação do meio; talvez este seja um exemplo que denuncia a necessidade de conjugar pontos de vista: a serra da Marofa tão discreta à luz das análises computacionais e referida por Cardoso como elemento de referência.

Por outro lado, há entre estes dois sítios uma intervisibilidade directa reduzida, mas quando falamos de intervisibilidade indirecta (por exemplo por meio de sinais de fumo) podemos afirmar que deveria ser eficaz. Este resultado parece bastante positivo quando tentamos falar em falibilidade dos SIG, porque está em consonância com análises espaciais feitas previamente por Jorge (2004: 595; 2005: 142-145) sem recurso aos SIG. Tal facto vem provar aquilo de que já desconfiávamos: a eficiência do SIG aplicado à arqueologia, pois de uma forma mais rápida foi possível concluir o mesmo que a autora. O que, no entanto, não significa que se deva sobrevalorizar os SIG em detrimento da percepção humana.

Falta, porém, comentar o carácter complementar destas duas bacias de visão: são praticamente inexistentes os sítios onde se tocam e juntas formam um ângulo cego a sudoeste. Este ângulo cego faz-nos pensar na possibilidade de existir um outro sítio de referência que o colmate. Ao adicionarmos novas bacias de visão a partir de Santa Columba e Montes percebemos que cobrimos esse ângulo (Fig.7). Isto, por sua vez, alerta-nos para a possível importância e necessidade de intervenção nestes sítios, que poderiam ter funcionado como recinto (Montes) e como especificidade geomorfológica com ocupação (Santa Columba), de acordo com os trabalhos de Cardoso (2007).

Estas constatações fazem pôr em evidência a possível existência de uma ocupação territorial tipo teia, onde os entrecruzamentos corresponderiam a sítios estrategicamente implantados ou por questões de ordem funcional ou por questões de ordem simbólica ou por questões de ordem funcional e simbólica, e onde pessoas e materialidades deveriam circular. Perante este cenário é tentador especular sobre a existência de núcleos interdependentes que formariam uma espécie de "aldeia", se voltarmos a observar a figura 2 e a compararmos com as bacias de visão damos conta que Castanheiro do Vento parece estar no controlo do núcleo da margem sul do Douro, enquanto Castelo Velho controla o núcleo que se situa em torno do rio Côa. Por outro lado, é interessante notar que na margem norte do Douro, concretamente na zona que Castanheiro do Vento controla, não há registo de sítios arqueológicos, resta saber se por falta de trabalho de campo se por efectivo vazio ocupacional.

Feita esta análise interessa ver, de todos os sítios aqui georreferenciados, quais aqueles que se encontram na área de influência destes dois recintos. Para tal executou-se o cálculo do Território de Marcha num raio de $10 \mathrm{~km}$ em torno dos dois recintos (Fig.8). Este cálculo é mais complexo que a simples criação de um buffer (criação de uma área de influência em linha recta) na medida em que considera o declive e as linhas de água e, com base nisso, cria uma superfície de custo que abrange o território que poderia ser explorado no dia-adia. Se considerarmos que 1 hora de marcha corresponde a $5 \mathrm{~km}$ (DAVIDSON \& BAILEY, 1984: 30), então podemos concluir o seguinte com base nesta operação:

(1) O sítio mais próximo de Castanheiro do Vento é Raza I (27), a uma distância de aproximadamente de $8 \mathrm{~km}$, o que corresponderia a 1 hora e 36 minutos de marcha até o sítio. Os sítios que se seguem a este em proximidade encontram-se já a uma distância significativa, que ultrapassaria as 2 horas de marcha. A linha de água mais próxima situase a pouco menos de $10 \mathrm{~km}$.

(2) Quanto a Castelo Velho o sítio mais próximo é o Alto de Santa Eufémia (28), a uma distância de aproximadamente $9 \mathrm{~km}$, o que corresponderia a 1 hora e 48 minutos de marcha; a exactamente $10 \mathrm{~km}$ de distância e, portanto, a 2 horas de marcha, documenta-se os Abrigos da Painova (24). Na proximidade da linha dos $10 \mathrm{~km}$ podemos ainda encontrar sítios como: Abrigos do Vale Ferreiro (23), Almoinhas I (42) e Vale do Minhoto (29). A linha de água mais próxima situa-se a cerca de $10 \mathrm{~km}$ de distância do recinto, porém o declive do terreno torna o acesso penoso. 


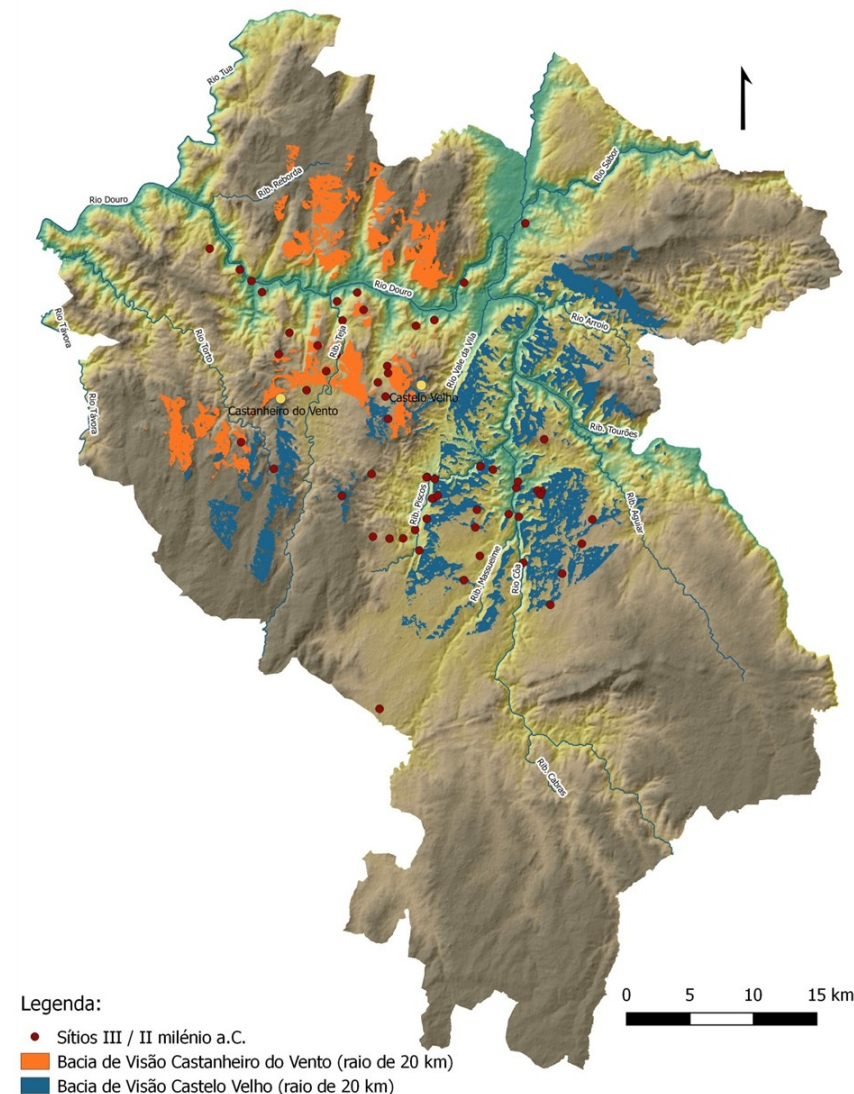

Fig. 6. Bacia de visão de Castanheiro do Vento e Castelo Velho. Executado com o módulo Viewshed Analysis do QGIS 2.10.1 Pisa.

Fig.6. Viewshed of Castanheiro do Vento and Castelo Velho. Made by Viewshed Analysis, QGIS 2.10.1 Pisa.
Fig. 7. Bacia de visão de Castanheiro do Vento, Castelo Velho, Santa Columba e Montes. Executado com o módulo Viewshed Analysis do QGIS 2.10.1 Pisa.

Fig.7. Viewshed of Castanheiro do Vento, Castelo Velho, Santa Columba and Montes. Made by Viewshed Analysis, QGIS 2.10.1 Pisa.

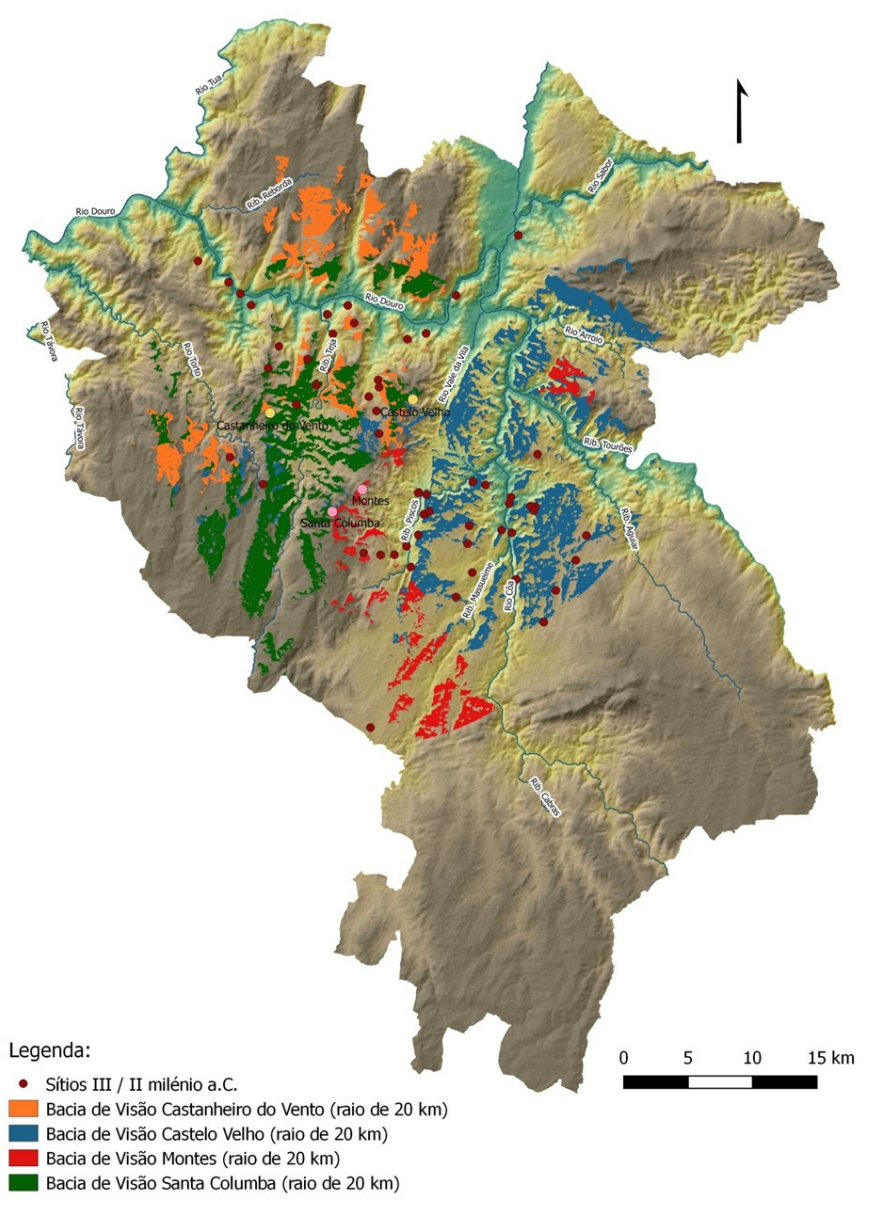




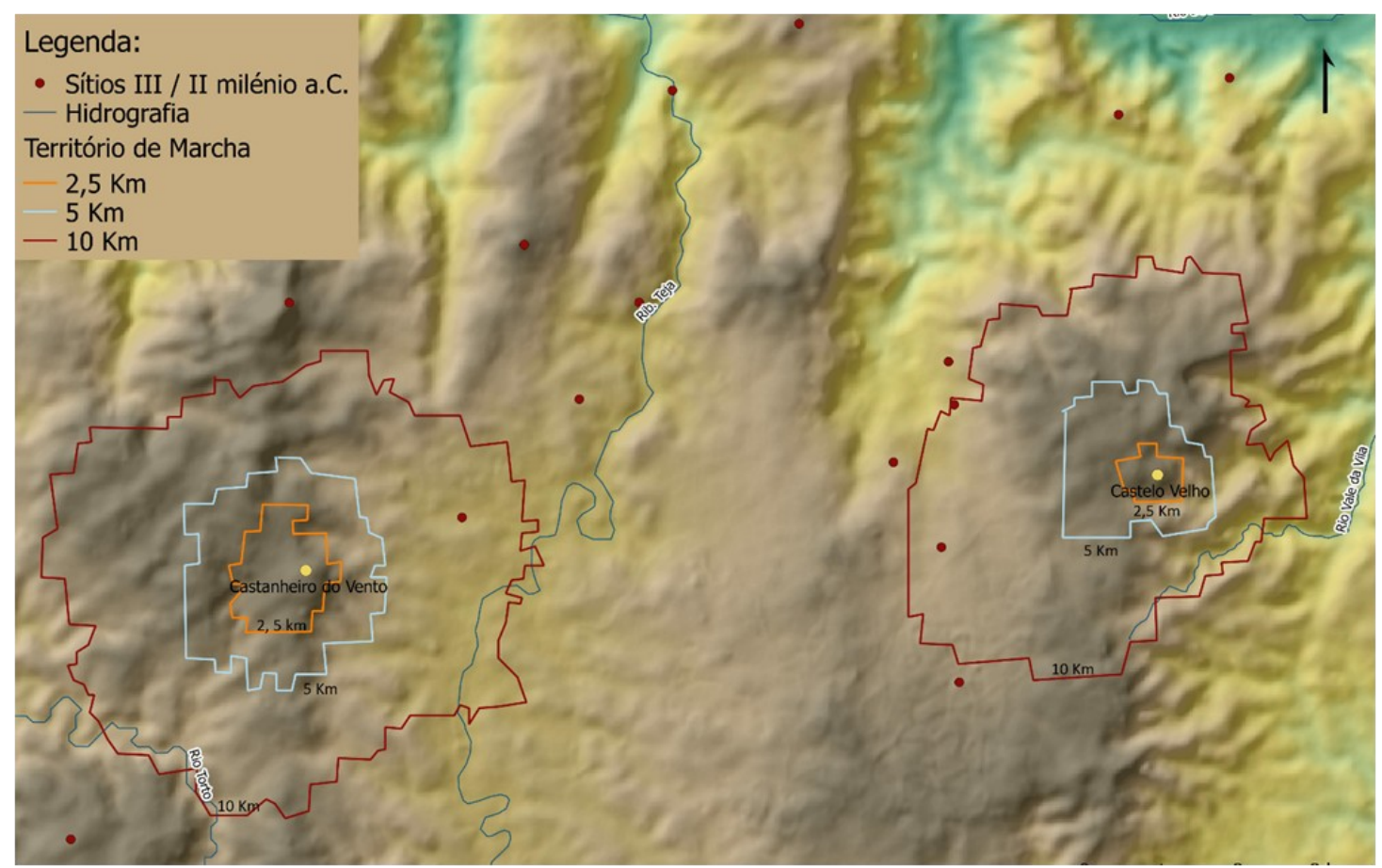

Fig. 8. Território de Marcha de $10 \mathrm{~km}$ a partir de Castanheiro do Vento e Castelo Velho. Executado com GRASS, QGIS 2.10.1 Pisa.

Fig. 8. Marching territory of $10 \mathrm{~km}$ from Castanheiro do Vento and Castelo Velho. Made by GRASS, QGIS 2.10.1 Pisa.

Estes exercícios, embora muito interessantes por nos permitirem pensar sobre a possibilidade de uma organização espacial, não podem ser analisados de forma cega; além de que permanecerão necessariamente incompletos até que se saiba o carácter destes sítios arqueológicos. Neste momento o único contributo prático destas operações é permitir realizar questões prévias ao trabalho de campo: qual o sentido por trás da distribuição destes sítios? E de que ordem é esse sentido, funcional, simbólico ou simplesmente aleatório?? O que nos dizem as implantações em zonas altas, relativamente às de meia encosta ou vales? Importa ainda ver que a estipulação de distâncias em alguns destes mapas é uma criação contemporânea, o que por sua vez nos leva a questionar qual o significado, para estes homens, de $1 \mathrm{~km}$ de distância, ou seja, que custos / esforços é que essa deslocação implicaria?

\section{CONCLUSÃO}

Reflectir e estabelecer os limites de conceitos como território, lugar ou paisagem é fundamental para que possamos entender a forma como os homens do passado percepcionavam o mundo. Essa leitura será sempre, porém, complexa devido à liberdade de acção de que dispunham. Por outro lado, importa questionarmo-nos até que ponto conseguimos ler um espaço que foi abordado com uma estrutura cognitiva que não a nossa?

Os mapas produzidos permitiram entender que a ocupação do território no III e II milénio a.C. deveria ter funcionado de forma articulada e hierarquizada, mas a veracidade deste aspecto só pode ser atestada com as devidas intervenções arqueológicas no terreno, pelo que as análises produzidas funcionam, nesta fase e desde um ponto de vista muito prático, como um sinal daquilo que poderia ter sido e não como algo absoluto, possibilitando desta forma decisões mais ponderadas no contexto de futuros estudos e / ou projectos.

Se por um lado e com base no Heatmap entendemos que se definem dois núcleos de povoamento, por outro acaba por ser o núcleo mais a norte, situado a Sul do Douro entre o rio Torto e o rio Côa, que mais interessa pois é aí que se situam os sítios que melhor se conhecem nesta região Castanheiro do Vento e Castelo Velho. É precisamente a partir destes últimos sítios arqueológicos, ambos instalados em pontos altos e, por isso, visíveis na paisagem, que se desenvolveram outras análises, nomeadamente viewsheds, cujo cálculo nos permitiu entender o imenso alcance visual que ambos possuem num raio de $20 \mathrm{~km}$, acresce o facto deste domínio visual ser complementar; ao executarmos estas bacias de visão foi possível entender que existia um ângulo cego, o que faltava para que o controle visual estivesse assegurado a 360 graus, os sítios de Santa Columba e Montes parecem localizar-se em pontos que permitem preencher essa "falha". No seguimento do que se começou por dizer no início deste parágrafo, efectivamente há dois núcleos que se parecem criar, embora Castanheiro do Vento e Castelo Venho se situem 
ambos num desses núcleos a verdade é que, como mostram as viewsheds, Castanheiro do Vento tem o controle visual do núcleo onde se insere, enquanto Castelo Velho tem o controle visual do núcleo que se desenvolve na parte medial do rio Côa; esta constatação revela-se interessante na medida em que reforça a noção de controle e hierarquia, tal como as análises do Território de Marcha nos permitem especular sobre sítios satélite que poderiam ter algum grau de dependência relativamente ao sítio central.

A análise digital do espaço, feita com recurso aos SIG, é uma visão filtrada da realidade e o enquadramento do objecto que se representa é o de visão de pássaro, visão vertical / oblíqua que se opõem à horizontal, característica da percepção humana. Este tipo de análises costumam ser feitas à escala regional, pondo em relação os vários sítios, porém para que possamos entender o passado importa que se trabalhe nas várias escalas, da micro à macro, do sítio à região; optar por uma ou por outra será sempre fazer apenas uma parte do trabalho, pois cada uma à sua medida dá o seu contributo e impõe a sua importância.

Todos estes ângulos são necessários quando queremos reflectir sobre a forma como a paisagem era vivida pelos homens do passado, pelo que os SIG se devem unir ao método presencial. Todavia, a aplicação dos SIG na Arqueologia ainda não é uma prática generalizada, o que se explica em grande parte pelo tempo de formação necessário; além deste problema, conte-se ainda a disponibilidade de fontes cartográficas digitais, que nem sempre é a ideal. Por outro lado, as vantagens destes softwares nulificam a questão da formação, porque a longo prazo esse tempo gasto é compensado com a rapidez com que se podem realizar análises espaciais, como por exemplo traçar perfis topográficos à velocidade de um clique. Além disto importa salientar as vantagens ao nível da gestão da informação, a economia de espaço, a rapidez de consulta, a capacidade de correlacionar dados de forma rápida e eficiente ou ainda a possibilidade de associar elementos alfanuméricos e gráficos.

\section{AGRADECIMENTOS}

A João Muralha Cardoso pela disponibilidade, confiança, pelos dados que me pôs ao dispor.

A Marcos Osório pela disponibilidade, conselhos, pelo que sei sobre SIG.

\section{BIBLIOGRAFIA}

AlarCão, J. 1996. Para uma Conciliação das Arqueologias. Porto, Afrontamento.

AlarCão, J. 2000. A escrita do Tempo e a sua Verdade. Coimbra, Quarteto Editora.

Alarcão, J. \& JORGE, V. O. 1997. Pensar a Arqueologia, Hoje. Porto, SPAE.

Anschuetz, K. F.; Wilshusen, R. H. \& Scheick, C. L.
2001. An Archaeology of Landscapes: Perspectives and Directions. Journal of Archaeological Research, 9: 157-211.

Bettencour, A. M. \& Alves, L. B. 2009. Dos Montes, das Pedras e das Águas. Formas de interacção com o espaço natural da pré-história à actualidade. Braga, CITCEM / APEQ.

Cardoso, J. C. M. 2007. Castanheiro do Vento (Horta do Douro, Vila Nova de Foz Côa) - Um Recinto Monumental do III $^{\circ}$ e II ${ }^{o}$ milénio a.C.: Problemática do Sítio e das suas Estruturas à Escala Regional. Dissertação de Doutoramento apresentada à Faculdade de Letras da Universidade do Porto, edição policopiada.

CoIXẽo, A. N. S. 1996. Carta Arqueológica do Concelho de Vila Nova de Foz Côa. Vila Nova de Foz Côa, Câmara Municipal de Vila Nova de Foz Côa.

CRIADO BoAdo, F. 1999. Del Terreno al Espacio: planteamientos y perspectivas para la Arqueología del Paisaje. CAPA - Criterios y Convenciones en Arqueología del Paisaje, 6.

DAVIDSON, I. \& BAILEY, G. N. 1984. Los yacimientos, sus territorios de explotación y la topografia. Madrid, Boletín del Museo Arqueológico Nacional, 2: $25-$ 43.

FAGUdes, M. \& PiUZANA, D. 2010. Estudo teórico sobre o uso conceito de paisagem em pesquisas arqueológicas. Revista Latinoamericana de Ciencias Sociales, Vol. 8, n. ${ }^{\circ} 1: 205-220$.

Fry, G. L. A.; SKAR, B.; JeRPÅSEn, G.; BAKKeStuen, V. \& ERIKSTAD, L. 2004. Locating archaeological sites in the landscape: a hierarchical approach based on landscape indicators. Landscape and Urban Planning, 67: 97-107.

GARCíA SANJUÁN, L. 2005. Introducción al reconocimiento $y$ análisis arqueológico del território. Barcelona, Ariel.

GONZÁLEZ VILlAEScusA, R. 2006. Una disciplina denominada Arqueología del Paisaje. Apuntes de Ciencia y Tecnología, n. ${ }^{\circ}$ 20: 28-36.

JORGE, S. O. 1994. Colónias, fortificações, lugares monumentalizados, trajectórias das concepções sobre um tema do Calcolítico peninsular. Revista da Faculdade de Letras, $2^{\mathrm{a}}$ série, Vol. XI: 447-546.

Jorge, S. O. 2003a. Pensar o espaço da Pré-História Recente: a propósito dos recintos murados de Península Ibérica. In S. O. JoRGE (coord.), Recintos murados da Pré-História Recente: técnicas construtivas e organização do espaço: conservação, restauro e valorização patrimonial de arquitecturas pré-históricas, Porto, Faculdade de Letras da Universidade do Porto: 13-50.

JoRGE, S. O. 2003b. Cenografias monumentais préhistóricas: tópicos para uma reflexão. In V. O. JoRGE (coord.), Arquitectando Espaços: da Natureza à Metapolis, Porto / Coimbra, DCTP (FLUP) / CEAUCP (FCT).

JoRGE, S. O. 2004. O sitio como mediador de sentido: Caste -lo Velho de Freixo de Numão: um recinto monumental pré-histórico do Norte de Portugal. Porto, Estudos em Ho-menagem a Luís António de Oliveira Ramos, Vol. 2: 583-611.

Jorge, S. O. 2005. O Passado é Redondo. Dialogando com os Sentidos dos Primeiros Recintos Monumentais. 
Porto, Edições Afrontamento.

Jorge, S. O.; Baptista, L.; Gomes, S.; Oliveira, M. L.; VARela, J. M. \& Velho, G. 2007. A construção de um sítio arqueológico: Castelo Velho de Freixo de Numão. In S. O. Jorge; A. Bettencourt \& I. Figueiral (eds.), Actas do IV Congresso de Arqueologia Peninsular: A concepção das paisagens e dos espaços na Arqueologia da Península Ibérica, Faro: 77-85.

JoRGE, S. O. \& RuBINos, A. 2002. Absolute chronology of Castelo Velho de Freixo de Numão (northern Portugal): data and problems. Journal of Iberian Archaeology, Vol. 4: 83-105.

Jorge, V. O. \& JoRGE, S. O. 2000. A "monumentalização" das paisagens durante a Pré-História: alguns contributos para um debate. Lisboa, ERA Arqueologia, 1, Colibril Era Arqueologia S. A.: 100-111.

Jorge, V. O.; Cardoso, J. M.; CoIxão, A. S. \& Pereira, L. S. 2002. Castanheiro do Vento, and the significance of monumental Cooper and Bronze Age site in the northern Portugal. In C. SCARRE (ed.), Monuments and Landscape in Atlantic Europe, Londres, Routledge: $36-50$.

Jorge, V. O.; Cardoso, J. M.; Pereira, L. S. \& CoixÃo, S. A. 2003a. Castanheiro do Vento, a late prehistoric monumental enclosure in the Foz Côa region, Portugal - recente research (1998-2002). Journal of Iberian Archaeology, Vol. 5: 137-162.

Jorge, V. O.; Cardoso, J. M.; Pereira, L. S. \& Coixão, S. A. 2003b. O recinto Pré-histórico de Castanheiro do Vento (Horta do Douro, Vila Nova de Foz Cõa): balanço sucinto das pesquizadas realizadas de 1998 a 2003. Portugalia, Vol. XXIV: 5-24.

LuCAmBIo, F. 2008. Estimador Kernel da função de densidade. (Última consulta a 27 de Setembro de 2016: http://docplayer.com.br/17339581-Estimador-kernel -da-funcao-de-densidade.html).

Muralha, J. C. M.; Carvalho, B.; Vale, A.; Gomes, S. \& Jorge, V. O. 2012. Sintese dos trabalhos arqueológicos em Castanheiro do Vento. Campa- nha de 2011. Cõavisão. Economia, Ciência e cultura, n. ${ }^{\circ} 14: 131-138$.

OREJAs, A. 1995. Del "marco geográfico" a la Arqueología del paisaje. La aportación de la fotografia aérea. Madrid, Monografías, 15, CSIC.

Orejas, A. 1998. El estudio del Paisaje: visiones desde la Arqueología. Arqueología del Paisaje, 19-20: 9-19.

OREJAS, A.; RUIZ DEL ÁrBol Moro, M. \& LóPEZ JIMÉNEZ, Ó. 2002. Los registros del paisaje en la investigación arqueológica. Archivo Español de Arqueología, 75: 287-311.

OsóRIo, M. e Salgado, T. 2007. Um Sistema de Informação Geográfica aplicado na Arqueologia do Município do Sabugal. Praxis Archaeologica 2: 9-22.

PellinI, J. R. 2008. Movimento e GIS: uma percepção da paisagem. Habitus, v. 6, n. ${ }^{\circ} 1$ / 2: 171-186.

SÁNCHEZ Yustos, P. 2010. Las dimensiones del paisaje en Arqueología. MUNIBE (Anropologia-Arkeologia), n. ${ }^{\circ} 61:$ 139-151.

Tilley, C. 1994. A Phenomenology of Landscape: Places, Paths and Monuments. Oxford, Berg.

UnwIN, D. 1981. Introductory spatial analysis. Londres, Methuen.

Vale, A. M. 2008-2009. Castanheiro do Vento (Horta do Douro, Vila Nova de Foz Côa). Alguns apontamentos acerca do dispositivo arquitectónico. Portugalia, Vol. XXIX-XXX: 43-60.

Vale, A. M.; CARdoso, J. M. \& Jorge, V. O. 2006. Recintos Murados e / ou Colinas Monumentalizadas no Nordeste de Portugal? O Caso de Castanheiro do Vento, Vila Nova de Foz Côa. In M. CORREIA \& V. O. JORGE (eds.), TERRA: Forma de Construir, Lisboa, Argumentum: 98-105.

Zedeño, Ma. N. 2008. The Archaeology of Territory and Territoriality. In B. DAVID \& J. THOMAS (eds.), Handbook of Landscape Archaeology, Califórnia, Left Coast Press. 